\title{
นึ่NIVERSITAS
}

Revista de Ciencias Sociales y Humanas de la Universidad Politécnica Salesiana

https://doi.org/10.17163/uni.n32.2020.07

\section{Corporativismo y representación política en Ecuador: el Consejo Nacional de Trabajo y Salarios}

\author{
Corporatism and political representation in Ecuador: the National \\ Council on Work and Salaries
}

\author{
Soledad Stoessel \\ IdIHCS (Universidad Nacional de La Plata-CONICET) \\ soledad.sto@gmail.com \\ Código Orcid: https://orcid.org/0000-0003-1872-5758
}

\begin{abstract}
Resumen
El texto presenta los resultados de una investigación que exploró la dinámica de una institución corporativa en Ecuador: el Consejo Nacional de Salarios durante el período 2007-2017. Esto se abordó a partir de dos dimensiones: su diseño institucional y la disputa alrededor de la representación política. Se estudiaron las implicancias de ambas en la gestión del conflicto entre el capital y el trabajo, el alcance democrático de la institución y la autonomía estatal para controlar la rectoría de la política salarial. La investigación se apoyó en una estrategia metodológica que articuló análisis normativo, hemerográfico y de documentos oficiales, y entrevistas a informantes clave. Algunas conclusiones refieren a la disputa por las reglas de la representación política de sindicatos y cámaras empresariales, el reforzamiento del poder del capital, y la orientación incluyente del Consejo al haber abierto la participación a trabajadores históricamente excluidos.
\end{abstract}

\section{Palabras clave}

Corporativismo, representación política, Estado, conflictos salariales, democracia, Revolución Ciudadana.

\begin{abstract}
The aim of this paper is to present the results of the research carried out to explore the dynamics of a corporate institution in Ecuador: The National Council on Salaries during the period 2007-2017. It was approached from two dimensions: its institutional design and the dispute around political representation. The implications of both dimensions in the management of the conflict between capital and labor, the democratic scope of the institution and the state autonomy to control the wage policy. The research was based on a methodology that combined regulatory, journal and official document analysis, and key informant interviews. Some conclusions refer to the rules of political representation of trade unions and business chambers, the reinforcement of the capital power, and the inclusive orientation of the Council in opening participation to historically excluded workers.
\end{abstract}

\section{Keywords}

Corporatism, political representation, State, wage conflicts, democracy, Citizens' Revolution.

Forma sugerida de citar: Stoessel, S. (2020). Corporativismo y representación política en Ecuador: el Consejo Nacional de Trabajo y Salarios. Universitas, 32, pp. 139-156. 


\section{Introducción}

En 2007, el Gobierno de la Revolución Ciudadana (RC) en Ecuador llegó en un contexto de crisis de la representación política. Los canales de representación clásicos habían perdido legitimidad. Tanto la representación partidaria, como la corporativa - vía gremios y organizaciones sectoriales - habían mostrado sus límites para garantizar inclusión social y estabilidad política. El cántico expresado durante las jornadas de abril 2005 que terminaron con la destitución de Lucio Gutiérrez - "que se vayan todos"daba cuenta de dicho hartazgo con la política institucional y partidaria. En este marco, el nuevo gobierno enfrentó diversos desafíos. Por un lado, reformar el Estado que había quedado desguazado en sus funciones de coordinación social y económica. Por otro, reconfigurar las formas de intermediación socio-política a partir de modificar los patrones de interacción legados de décadas previas. Ambos desafíos respondían a lo que desde el proyecto de la RC comenzó a denominarse el "problema del corporativismo" (Senplades, 2014).

Una de las líneas de reforma estatal estuvo abocada a resolver la "captura" estatal que durante el neoliberalismo habían perpetrado diversos grupos sociales con intereses privados a través de la ocupación de espacios de poder dentro del Estado, obteniendo sus dirigentes cuotas de representación en consejos, comisiones y órganos rectores de las políticas públicas. Para el Gobierno, esta era una forma perniciosa de vinculación socio-estatal que debilitaba la orientación pública hacia el bien común. Tal lectura no diferenciaba tipos de intereses, desconociendo la naturaleza y jerarquía que existe entre, por ejemplo, aquellos provenientes de los grandes banqueros y los del movimiento indígena. Así, para la Revolución Ciudadana (RC), la lucha contra el corporativismo era fundamental para recuperar al Estado y establecer una gestión pública impermeable a específicos intereses. Esto significaba cambiar el diseño institucional del Estado y colocar nuevas reglas de representación política.

Una de las áreas de política donde el "problema del corporativismo" no se tradujo en la extinción de cuotas de representación sectorial ${ }^{1}$ pero sí en

1 Instituciones vinculadas a las finanzas, comercio exterior, recursos naturales y transporte sufrieron reformas que modificaron la composición de los órganos rectores, consejos y comisiones institucionales, o directamente fueron eliminadas. Por ejemplo, la Ley de Recursos Hídricos, una de las más conflictivas en su aprobación, estipuló que la autoridad del agua se conformaría principalmente por 
diversas reformas para intervenir su funcionamiento, fue el de las relaciones capital-trabajo, particularmente la institución que las regula: el Consejo Nacional de Salarios (CONADES), convertido en Consejo Nacional de Trabajo y Salarios (CNTS) desde 2016. Esta institución es un organismo de composición tripartita (sindicatos, empresarios y Estado como actores principales) y durante el período 2007-2017, no solo pervivió como espacio formal de negociación entre distintos intereses, sino que sufrió ciertas transformaciones, tanto promovidas por el propio gobierno, como "desde abajo" por los sindicatos y cámaras empresariales.

Este texto presenta los resultados de una investigación que exploró la dinámica de esta institución corporativa a partir de dos dimensiones: su diseño institucional y la disputa alrededor de la representación política al interior de aquella. La investigación se apoyó en una estrategia metodológica de tipo cualitativa que combinó tres técnicas: análisis de archivos normativos que regulan el CONADES/CNTS y de las actas públicas de sus reuniones, comisiones sectoriales y conformación de los colegios electorales $;{ }^{2}$ entrevistas realizadas durante abril 2019 a exfuncionarios públicos con conocimientos sobre el CONADES/CNTS, dirigentes sindicales y de las cámaras empresariales que participaron como delegados en el pleno del Consejo; ${ }^{3}$ y revisión hemerográfica de tres periódicos de circulación nacional (El Telégrafo, El Universo y El Comercio) para identificar eventos que involucraron el objeto de estudio en cuestión.

En términos de debate téorico-empírico, esta investigación dialoga con dos tesis principales que han atravesado la cuestión de las relaciones socioestatales durante el período gobernado por la RC. Algunos trabajos sostie-

miembros del Poder Ejecutivo, no por representantes indígenas como demandaba la CONAIE. El directorio de la Agencia Nacional de Tránsito expulsó de su seno la representación formal que los transportistas ejercían y también se conformó por funcionarios del Poder Ejecutivo. Para ahondar en los campos de política y los organismos que fueron "descorporativizados", ver los trabajos de Ramírez Gallegos (2012); Stoessel (2017); Ospina Peralta (2009).

2 Esta información fue brindada por el Ministerio de Trabajo (ex Relaciones Laborales), con el oficio número MDT-DAS-2019-0016 en abril 2019.

3 Las personas entrevistadas durante abril 2019 fueron las siguientes: Mauro Andino (exviceministro de Relaciones Laborales de Ecuador, $\mathrm{N}^{\circ} 1$ ); Lenin Cadena (exsecretario del CONADES, $\mathrm{N}^{\circ} 2$ ); Liliana Durán Aguilar (Asambleísta Nacional y exdelegada en el CONADES, №3); Rodrigo Gómez de la Torre (delegado de los empleadores en el CNTS, titular durante 2016-2019, N44); Xavier Sisa (delegado de los empleadores, suplente 2012-2013 y titular 2016-209, Director Jurídico de la Cámara de Industrias y Producción, Nº5); Pablo Serrano (Presidente de CEOSL, Nº6); Oswaldo Chica (Presidente de la Central Unitaria de Trabajadores, Nº7). 
nen la tesis de la des-corporativización del Estado. Este supuesto sostiene que la política gubernamental durante esa etapa estuvo orientada a suprimir o regular los arreglos corporativos que se habían pergeñado durante el neoliberalismo con el objetivo de que el Estado gane márgenes de autonomía política (Ramírez Gallegos, 2012; Posso, 2013). El alcance de mayor autonomía vendría dado, entonces, por poner coto a "la capacidad de veto de determinados grupos de poder (dentro y fuera del gobierno) y de ciertos anillos burocráticos" (Ramírez Gallegos, 2012, p. 367).

Otros trabajos, también enmarcados en la discusión en torno al corporativismo, sin contradecir la tesis anterior, refuerzan otro aspecto en detrimento del elemento estatal. Analizan la lucha contra el corporativismo como la forma en que el gobierno debilitó la participación directa de organizaciones y movimientos en la toma de decisiones públicas y produjo así, cierta pasividad de los actores sociales (Ospina Peralta, 2009; Marega, 2015). Este trabajo procura aportar a este debate a partir de ofrecer otros rasgos en torno al corporativismo ecuatoriano: en determinadas áreas de política, el gobierno, en lugar de suprimir los arreglos corporativos, los reforzó con una cierta disposición para funcionalizarlos a su favor. Este fue el caso de la gestión del transporte público (Stoessel, 2017) y las relaciones laborales, como se analiza en este texto. Esto no implicó un necesario debilitamiento de los actores sociales involucrados, sino que dicho resultado estuvo sujeto al peso de los intereses en cuestión, de las relaciones de fuerza entre Estado, gobierno y actores, y a ciertos constreñimientos estructurales que marcaron el terreno de las opciones de acción política.

El texto se organiza en tres secciones. En la primera, se contextualiza el surgimiento de la regulación de la relación capital-trabajo y la creación del Consejo en los años setenta. En la segunda, se presentan los elementos principales de su diseño institucional y sus transformaciones durante el período bajo estudio (2007-2017). Por último, se expone el tipo de representación reconfigurado en el seno del organismo y sus impactos en la tramitación del conflicto entre capital, trabajo y Estado.

\section{Regulación de las relaciones capital-trabajo: el surgimiento del CONADES}

Durante la década del treinta en la región latinoamericana, diversos países atravesaron procesos de transformación institucional para contener los 
conflictos y resistencias cada vez más acuciantes protagonizados por los trabajadores que ya comenzaban a organizarse en sindicatos y centrales sindicales. Así, se crearon varias instituciones como ministerios de Trabajo, organismos de seguridad social, consejos salariales y económicos. El caso de Ecuador no estuvo exento de dichos procesos. Desde la década del veinte, también los trabajadores ecuatorianos comenzaron a demandar mayor participación en la toma de decisiones públicas y ampliación de derechos sociales (Achig \& Neira, 1989). Respuestas estatales como la creación del Ministerio de Previsión Social y Trabajo, y el control estatal de capital extranjero vinculado a empresas petroleras para regular las condiciones laborales y reclamar participación en las ganancias, fueron algunas (Coronel, 2013). Para la década del setenta, el conflicto entre el capital y el trabajo ya escalaba a otro nivel. Aparecieron los primeros intentos de conformar un frente de trabajadores a partir de la convergencia de distintas centrales sindicales como CEDOC, CTE y CEOSL. Fue en el período 1971-1979 que se constituyó el 42\% de las organizaciones sindicales de la etapa comprendida entre 1920-1990 (Velasco, 1987). La huelga de noviembre de 1975 marcará el nacimiento del Frente Unitario de los Trabajadores (FUT) y desde entonces los gobiernos tendrían abiertos diversos frentes, tanto con las elites empresariales como con los trabajadores que mostraban por entonces un fuerte activismo social, incluso durante gobiernos represivos y autoritarios como el de León Febres Cordero.

La creación del Consejo Nacional de Salarios (CONADES) en 1974 a cargo del gobierno militar de Guillermo Rodríguez Lara, en efecto, estuvo orientado a contener los conflictos entre el capital y el trabajo. El boom petrolero en un contexto en que el precio del banano y su producción entraron en declive, favoreció, junto con el fin progresivo del huasipungo, el surgimiento de una masa de trabajadores asalariados. Asimismo, la sociedad ecuatoriana experimentó el incipiente aparecimiento de una nueva burguesía (industrial, comercial y financiera) y la expansión progresiva de una clase media urbana en Quito y Guayaquil (Oleas, 2013, p. 23).

El CONADES surgió por medio de un decreto presidencial ( $\left.\mathrm{n}^{\mathrm{o}} 318\right) \mathrm{y}$ un acuerdo ministerial (número 039-A). Se estableció como un organismo técnico, consultivo y tripartito en que estarían representados los trabajadores del sector privado, los empresarios y el Estado para definir el salario básico de mutuo acuerdo. La remuneración del trabajador no sería inferior al salario mínimo vital o al fijado por las Comisiones Sectoriales -órgano que conformaba el CONADES - para cada rama de actividad. El CONADES se 
encargaría de elaborar análisis acerca de las estructuras ocupacionales, los esquemas salariales y la productividad. Los sindicatos y empresarios tendrían voz, pero no voto, y las decisiones allí adoptadas no serían vinculantes.

Durante los años de hegemonía neoliberal, el CONADES se dedicó especialmente a la discusión salarial. Las condiciones materiales y el poder de negociación de los trabajadores ya se habían ampliamente debilitado a raíz del conjunto de políticas de ajuste estructural que comenzaron a implementarse en la década del ochenta con el gobierno empresarial de Febres Cordero y continuaron en los sucesivos gobiernos. ${ }^{4}$ Estas medidas terminaron institucionalizándose con la Constitución de 1998. El FUT, el frente sindical que tenía representación dentro del CONADES, comenzó a declinar (Ycaza, 1991). Los empresarios, por el contrario, continuaron ejerciendo influencia y fortaleciéndose a través de otros mecanismos, como las alianzas con partidos políticos de derecha, la ocupación de cargos ejecutivos estratégicos, el financiamiento de campañas electorales y el lobby para obtener la aprobación de determinadas leyes.

En 2000 se aprobó la ley conocida como "Trole 1" que modificó algunos artículos del Código de Trabajo (CT) con el pretexto de incentivar la competencia empresarial y la inversión. Estipuló la incorporación de la contratación por horas y que sean las partes las que acuerden la remuneración salarial por hora trabajada (Aguiar, 2007). El CONADES siguió encargándose de definir el monto del salario básico unificado, pero de forma anual y ya no semestral. En la mayoría de los casos durante los años noventa, no se llegó a un acuerdo dentro del CONADES, por lo que, según estipulaba la ley, era el Ministro el que debía fijar el salario. Él tenía la última palabra y debía incrementar el salario en la misma cantidad que la inflación proyectada por el Banco Central. Por lo general, esto entraba en contradicción con el artículo 126 del CT que establecía que los criterios para definir el salario debían residir, además de la inflación, en la satisfacción de las necesidades básicas, el rendimiento del trabajo y el desgaste físico.

Con el cambio de siglo y el inicio del gobierno postneoliberal de la RC, el campo de las relaciones laborales fue reformado. La cuestión del "mundo del trabajo" y sus condiciones de funcionamiento fue uno de los nudos

4 La flexibilización laboral se institucionalizó en la Ley de Régimen de Maquila y de Contratación Laboral a Tiempo Parcial (1990) que regula la contratación laboral de corta duración; la Ley 133 Reformatoria al Código de Trabajo (1991) que duplica el número mínimo de trabajadores (de 15 a 30) exigido para la conformación de toda organización sindical. La tasa de desempleo era del $6 \%$ en 1990, y en 1999 aumenta al 15\%. Datos extraídos del Instituto Nacional de Estadísticas de Ecuador. 
temáticos centrales y la que mayor consenso generó entre los trabajadores y el gobierno durante el proceso constituyente (2008-2009). Ni bien se instaló la Asamblea Constituyente, el Gobierno anunció la aprobación del Mandato Constituyente 8 para eliminar la tercerización e intermediación laboral y cualquier forma de precarización laboral. La Constitución lo ratificaba en su artículo 327. La Carta Magna también incluyó varios artículos que reglamentaban las relaciones laborales para mejorar sus condiciones. Así, obligaba al Estado a garantizar los derechos al trabajo y a la seguridad social (artículos 33 y 34), reconocía el trabajo no remunerado del hogar y autónomo (artículo 34), prohibía el trabajo de los niños menores a 15 años (art. 46), estipulaba que la política económica debía impulsar el pleno empleo y valorar todas las formas de trabajo, garantizaba el derecho y libertad de organización de los trabajadores y empleadores (art. 326) y el estímulo por parte del Estado a la creación de organizaciones sindicales (326) (Herrera, 2015). También el Gobierno aumentó el salario mínimo e implementó varias reformas en el CONADES. Esta institución corporativa fue una de las pocas que sobrevivió a la lucha emprendida por el gobierno contra aquellos organismos cuyo funcionamiento o composición se consideraba corporativa.

\section{La disputa por el diseño institucional}

Hay tres cuestiones referidas al diseño institucional del Consejo Nacional de Salarios (CONADES) durante el período 2007-2017 que son fundamentales presentar porque conllevaron efectos sobre la capacidad estatal para intervenir en la dinámica de la institución y en la configuración de la representación política.

En primer lugar, la conformación del Consejo. Durante 2007-2015, se componía por un representante gubernamental, uno de las Federaciones Nacionales de Cámaras de Industrias, de Comercio, de Agricultura, de la Pequeña Industria y de la Construcción, y otro de las centrales de trabajadores legalmente reconocidas (Artículo 3), un total de tres. Dicha composición será modificada en 2015 y será extendida a cinco, ampliando a uno más el representante por el sector empresarial y trabajador. A los fines de las dimensiones acá investigadas, lo más interesante respecto a la composición del Consejo sucede en 2016 cuando el gobierno realiza una modificatoria respecto a los actores convocados para participar dentro del Consejo. Mediante 
Acuerdo Ministerial $\mathrm{N}^{\circ} 44$, se sustituye la frase "centrales, confederaciones, frentes y/o uniones de personas trabajadoras más representativas de ámbito nacional legalmente reconocidas como tales" por "centrales, confederaciones, frentes, organizaciones y/o uniones de personas trabajadoras más representativas de ámbito nacional". Se quita el criterio de que sean legalmente reconocidas, ampliando así el rango de organizaciones habilitadas para disputar la representación de los sectores gremiales. En efecto, se aprueba la participación de organizaciones nuevas (Asociación de Trabajadoras Remuneradas del Hogar), o de otras antiguas que históricamente habían quedado excluidas por no tener el reconocimiento legal (trabajadores autónomos). Estas organizaciones comenzaron a formar parte de la nueva Central Unitaria de Trabajadores (CUT), surgida en 2014 y que desde 2016 obtuvo cuotas de representación dentro del Consejo, provocando una disputa por la representación con el FUT, quien hasta ese momento tenía el monopolio. Desde 2016, por primera vez, los dos delegados de parte de los trabajadores pertenecen a dos organizaciones diferentes y enfrentadas entre sí (FUT y CUT).

En este punto, han existido distintas controversias entre los actores sociales implicados. Tanto los dirigentes empresariales como los dirigentes del FUT, coincidieron en afirmar que la ampliación de los delegados se debió a una estrategia política del gobierno para fragmentar al sector de los trabajadores y generar mayor dificultad para que éstos y empresarios arribaran a un consenso (testimonios de las entrevistas 4, 5 y 6). En cambio, para los dirigentes provenientes de la CUT, la decisión del gobierno respondió a su intención de democratizar el acceso a la institución y reparar décadas de exclusión de trabajadores que hasta el momento no habían logrado organizarse, o lo habían hecho en estructuras no reconocidas legalmente.

El análisis comparativo de las negociaciones salariales por Comisiones Sectoriales desde 2011 hasta 2017 arroja diferencias respecto al período en que el FUT ostentaba el monopolio de la representación y el período posterior cuando ya no lo tiene. Durante el primero, los representantes laborales lograron negociar el salario en casi 1 de cada 3 reuniones. Desde 2014 y 2015 esto se reduce a 1 de cada 10. Sin embargo, en 2017 y ya con el dominio de la CUT, se vuelve a los mismos números que el primer período de monopolio de la representación en manos del FUT. En ese sentido, la incorporación de nuevos sujetos de representación sí dificultó la concreción de acuerdos. Por otro lado, también es cierto que la hegemonía de la CUT implicó una apertura a la representación de nuevas categorías laborales que no tenían presencia. 
La segunda cuestión es la forma de elección de los representantes dentro del Consejo, la cual también sufrió algunos cambios. Hasta 2015, el Acuerdo Ministerial $N^{\circ} 59$ vigente desde el año 2000 reglaba que el Ministro convocaría a las federaciones nacionales de las cámaras de industrias y las centrales sindicales de los trabajadores legalmente reconocidas para que, por medio de un elector designado por cada una de éstas, procedan a la elección del representante único y su suplente ante el CONADES. Esta forma de elección dejaba un amplio margen de negociación al interior de los respectivos espacios gremiales. Sin embargo, desde 2015 este procedimiento se modifica en dos aspectos. Por un lado, si en determinada fecha las federaciones de empleadores y centrales sindicales no llegaban a designar un elector, pues el Ministro del Trabajo podía designarlos (Acuerdo Ministerial $\mathrm{N}^{\circ}$ 240, Art. 10). Asimismo, en caso de que no existiera acuerdo dentro de los espacios gremiales, el Estado se arrogaba la facultad de escoger el delegado, entrando de esta forma en la disputa por la representación de las partes. En efecto, esto sucedió en 2014 cuando la aparición de las nuevas centrales susceptibles de participar en el Consejo derivó en que no hubiera acuerdo entre los dirigentes del trabajo para la elección del delegado. El Ministro intervino y seleccionó a un dirigente de la CUT, afín al gobierno. Las nuevas reglas de la representación, así, favorecían la acción gubernamental y un relativo control de la discusión al interior de la institución.

El tercer punto alude al tránsito del CONADES hacia el Consejo Nacional de Trabajo y Salarios (CNTS). Será recién a partir del año 2015, con el Acuerdo Ministerial No 240, que el CONADES pasa a denominarse CNTS, para abarcar la discusión de políticas laborales, no sólo salariales. Varios factores lo promovieron: deterioro económico desde $2014,{ }^{5}$ surgimiento de nuevos trabajos, así como modalidades laborales que requerían discusiones en torno a su regulación, y además, las crecientes dificultades en el frente político que el Gobierno comenzó a afrontar desde 2013, año en que paradójicamente la RC había mostrado un rotundo poderío electoral. El Gobierno, habiéndose sumado cada vez más actores opositores, debía ceder ante algunos de los reclamos vertidos por estas organizaciones.

Tanto los dirigentes de los trabajadores como de los empresarios habían comenzado a manifestar desde 2010 a las autoridades la necesidad de que la

5 Desde 2014, el crecimiento económico se detuvo, el empleo descendió y las reservas se deterioraron, debido, en lo fundamental, a la baja del precio internacional del petróleo, fuente principal de ingresos del Ecuador. 
institución esté facultada para discutir otras cuestiones referidas al empleo y trabajo, como condiciones laborales - reclamo de los trabajadores - o estructuras ocupacionales y tipos de contratos - reclamo de los empresarios- - Si bien las Comisiones Sectoriales y Mesas de Diálogo - espacios existentes dentro del Consejo, también de composición tripartita y similar dinámica que el Pleno del Consejo - funcionaban de facto para discutir otros temas más allá de los salariales, se activaban:

Muy ocasionalmente ya que si el Ministro no convoca cuando lo obliga la ley, entonces las mesas no se reúnen. Los que comenzamos a reclamar y quejarnos por este mal funcionamiento somos los empresarios, porque la discusión de temas laborales estaba siendo tramitada en la Asamblea, como ocurrió con la "Ley de Feriados" en la cual nosotros en tanto participantes oficiales del consejo no tuvimos voz ni voto. Nosotros deberíamos haber discutido esa cuestión para que luego pase a la Asamblea con un texto ya consensuado por los interesados. (entrevista $\mathrm{N}^{\circ} 5$ )

Los testimonios y el análisis de cómo efectivamente funcionaron el nuevo Consejo (CNTS) ratificaron la disposición que históricamente tuvieron los empresarios para influir e intervenir en el diseño de las políticas y en las instituciones estatales (Burbano de Lara, 2006). El reclamo de ser consultados por el Estado y la instalación de arreglos corporativos como si aquel tuviera la obligación de hacerlo fue una constante de las elites desde la década del ochenta. Las palabras del viceministro de relaciones laborales entrevistado lo confirmaron. Argumentó que eran "los empresarios los que querían discutir en el Consejo la cuestión laboral, por ejemplo, temas de contratos, ellos creían que la Ley (Orgánica) de Justicia Laboral había significado un perjuicio para ellos" (entrevista $\mathrm{N}^{\circ} 1$ ).

Por parte de los trabajadores, el representante delegado en el CNTS también señaló algo en aquella dirección:

El CONADES es convocado solamente cuando se lo necesita y no para hacer un trabajo técnico (...) hay que ir preparando la discusión a lo largo del año, hacer un análisis técnico por ramas de trabajo viendo cuánto se gana, cuáles las condiciones del país. (entrevista $\mathrm{N}^{\circ} 7$ )

Por su parte, la dirigencia del sindicato de trabajadoras remuneradas del hogar del trabajo también apoyaba dicho cambio: "era necesario comenzar a discutir por ejemplo la cuestión de género en el trabajo, en las políticas la- 
borales" (entrevista $\mathrm{N}^{\circ} 3$ ). En ese sentido, se observa cómo el cambio de las funciones del CNTS fue resultado de las reivindicaciones de los actores implicados, todos motivados por su voluntad de reforzar su poder al interior del organismo. Esto, no obstante, no modificaba el margen de acción del Estado, el cual seguía revistiendo en última instancia la facultad para acogerse o no a lo que allí se consensuara.

\section{La representación corporativa en conflicto}

Entre los años 2010 y 2013 se evidencia dentro del Consejo un monopolio de la representación gremial en manos del FUT. De tendencia clasista y combativa (y opositora al Gobierno correísta a partir del período postconstituyente), dicho Frente se conforma por distintas organizaciones gremiales, entre las cuales están: la Confederación Ecuatoriana de Organizaciones Clasistas Unitarias de Trabajadores (CEDOCUT), la Confederación Ecuatoriana de Organizaciones Sindicales Libres (CEOSL), la Unión General de Trabajadores del Ecuador (UGTE) y la Confederación de Trabajadores del Ecuador (CTE). Hasta 2014 estas cuatro organizaciones han votado en colectivo para designar al representante de los trabajadores en el CONADES. Entre 2010 y 2013, otras organizaciones (no afiliadas al FUT) no siempre han acompañado sus posturas. Entre ellas están la Confederación Ecuatoriana de Organizaciones Clasistas (CEDOC-CLAT) (un desprendimiento de la CEDOC en los años setenta) y la Confederación Ecuatoriana de Trabajadores y Organizaciones de la Seguridad Social (CETOSS). La primera se ha abstenido de votar las propuestas del FUT en los años 2010 y 2011. Mientras que la segunda, junto con la CEDOC-CLAT, no ha asistido a la votación del 2013. Solo en 2012, ambas centrales votan en conjunto con las agrupadas en el FUT.

Ahora bien, en 2014 con la aparición ya formalizada de la CUT, se produce el quiebre de dicho monopolio a cargo del FUT. Si se dialoga con las perspectivas clásicas de la ciencia política en torno al corporativismo que consideran el componente monopólico de la representación como su requisito (Schmitter, 1998), se puede afirmar que el componente corporativo de la institución se debilitó o mutó. El Gobierno comenzó a reconocer también a las centrales aglutinadas en la CUT, y desde 2014 la convocatoria realizada por el Ministerio del ramo a las centrales sindicales para conformar los colegios electorales encargados de escoger a los representantes fue dirigida 
también a todas las organizaciones pertenecientes a la CUT. Luego de cinco años, por primera vez el sector de los trabajadores encontró discrepancias para escoger a los delegados. Al evidenciarse una situación de empate, el Ministro quedó facultado, tal y como prescribe la norma, para elegir a los representantes de los trabajadores. Así fue como el Ministro eligió a Jaime Arciniega (de la CSE, nucleada en el PLE) como titular, y a Edgar Sarango (de la CTE, parte del FUT) como suplente, quienes durarían en el cargo dos años.

Ya para el año 2016, con la inauguración del CNTS, las centrales sindicales del FUT dejaron de participar definitivamente de la sesión del colegio electoral. Según un dirigente de la CEOSL, hacerlo hubiera significado legitimar a un organismo y a interlocutores que estaban operando según intereses particulares, sin apoyo popular y con el solo objetivo de perjudicar a los trabajadores. Participar con representantes hubiera sido un modo de legitimar un "Consejo gobiernista" (entrevista No6). Según el FUT, la aparición de la CUT estuvo aupada en la intención del gobierno de fragmentar y debilitar a la clase trabajadora y promover la construcción de una cúpula sindical "oficialista" que se sometiera a las decisiones del gobierno. En efecto, los dos representantes de los trabajadores dentro del CNTS posteriormente terminaron siendo asambleístas del partido gobernante (Alianza País). Por su parte, el delegado por parte de los trabajadores perteneciente a la CUT, sostuvo que participar en el Consejo (a diferencia de la decisión de sus colegas del FUT de no hacerlo) era una demostración hacia el gobierno y los empresarios de que "somos una Central abierta y de diálogo (...) un mensaje de que los trabajadores estamos en ese mismo nivel de discusión que los empleadores" (entrevista $\mathrm{N}^{\circ} 7$ ).

En la reunión de 2016, participaron el representante de la CUT, el de la CUTTAE y la representante de la Asociación de Trabajadoras Remuneradas del Hogar. Ese mismo año, con los dos delegados por parte de los trabajadores provenientes de la CUT, se logró, por primera vez en un hecho inédito luego de quince años, un consenso con el sector empresarial. Según el delegado por parte de los trabajadores:

Fue algo significativo, aunque la situación sociopolítica que vive el país no nos permite llegar a un aumento salarial como esperaríamos todos. Hay que ser responsables en eso y no lanzar cifras como hacía el FUT. El pequeño productor, el pequeño comerciante, que tiene una, dos, tres personas, tendrá que botarlos porque no podrá pagar ese incremento. Hay parámetros que nos da la OIT para poder hacer un cálculo de cuál es el incremento salarial. Con 
esa base, llegamos a un consenso. Me sentí satisfecho de que pudimos demostrar que se puede sentar a dialogar con los trabajadores. (entrevista $\mathrm{N}^{\circ}$ 7)

Este inédito acuerdo en el 2016 fue explicado por parte del delegado de los empresarios como un "acuerdo políticamente correcto, el empleo pleno en Ecuador se seguía perdiendo y no tenía sentido aumentar los salarios" (entrevista $\mathrm{N}^{\circ} 4$ ).

Si se desplaza la mirada hacia el campo de la representación empresarial, se observan amplias diferencias respecto a la representación del trabajo. No sólo no se evidencian fisuras como en este caso, sino que también se puede observar una sólida cohesión y unidad al interior del colectivo de cara a negociar con los trabajadores y el Estado. La continua presencia de Luis Poveda Velasco (de la Cámara de Industrias de Guayaquil) como representante durante 8 años consecutivos (2010-2017) es sintomático de aquello. Esto produce beneficios para el sector de los empresarios dado que dota a una sola persona de la suficiente experticia técnica y conocimiento práctico para colocarse en una mejor posición de negociación, que al mismo tiempo contribuye a aumentar su capital simbólico. Este poder empresarial aumenta cuando se debilita la fuerza de los otros participantes (trabajadores y gobierno), y se ve reforzado por dos factores: recursos económicos y fragmentación del campo sindical de los trabajadores. Tal como relató uno de los dirigentes empresariales (entrevista $\mathrm{N}^{\circ} 5$ ), que oficia como delegado por el sector industrial y de la construcción desde hace 8 años, las cámaras empresariales cuentan con mayores recursos económicos para poder contratar consultorías, estudios técnicos e informes estratégicos con los cuales posicionarse en mejores condiciones en las negociaciones colectivas. En palabras del empresario:

Llegábamos a las reuniones de las Comisiones Sectoriales y les presentábamos toda una serie de datos para argumentar nuestra posición sobre el monto salarial que debía aprobarse (...) los sindicatos no contaban con información, o por lo menos, mostraban datos que parecían no haberse consensuado con todas las centrales o federaciones de trabajadores.

El asesoramiento a los empresarios por parte de grandes consorcios económicos y think tanks los sitúa indefectiblemente en una mejor situación para enfrentar cualquier negociación. Incluso medidas que perjudicaron a las cámaras empresariales desde los inicios del gobierno de Rafael Correa como la inconstitucionalidad de volver compulsiva la afiliación de las em- 
presas a las cámaras, no afectaron el cúmulo de capitales (económicos y sociales) de las federaciones empresariales para posicionarse en las negociaciones. Esto fue ratificado en una entrevista con un dirigente del FUT, delegado durante 2011-2014, quien afirmó que era poco frecuente que los representantes de las federaciones de los trabajadores llegaran preparados a las comisiones sectoriales. En ese sentido, del lado de los trabajadores se propuso en algunas oportunidades que el Ministerio ofreciera capacitaciones para los delegados de los trabajadores que participaran en las comisiones sectoriales. Al día de hoy, dicha demanda aún no fue considerada.

El segundo factor del poderío empresarial está vinculado a la fragmentación del campo sindical que ya se presentó previamente. Desde que se quebró el monopolio de la representación a cargo del FUT, la elección de los delegados al Consejo fue objeto de conflicto entre las diversas centrales sindicales. En 2013, una nueva discrepancia afloró en el seno del Consejo relativa a la división entre trabajadores del sector privado y del sector público. Dirigentes de las centrales sindicales del FUT expresaron su disconformidad: "deben estar los representantes de las centrales sindicales que verdaderamente representan al sector privado" (actas de las reuniones de los consejos electorales). La cuestión por la incorporación de los trabajadores del sector público se convirtió en una querella desde entonces. Tanto los dirigentes del FUT como los dirigentes empresariales rechazaban que en el Consejo les otorgara representación y un espacio de participación. Para el delegado por parte del sector empresarial, "durante 2015-2017, los representantes de los trabajadores pasan a ser fundamentalmente dirigentes de los servidores públicos, eso era un problema, estábamos definiendo salarios con personas que representaban a trabajadores públicos y no a los privados". De esta forma, la disputa por la representación, sobre la legitimidad de qué actores debían o no gozar de representación política, fue una disputa en la que no solo terciaron las organizaciones sindicales enfrentadas, sino el propio gobierno - con la aprobación de que trabajadores del sector público puedan participar en el consejo- y los dirigentes del sector privado.

\section{Conclusiones}

Este texto exploró cómo el diseño institucional y la dinámica de un organismo como el Consejo Nacional de Salarios en Ecuador durante el perío- 
do 2007-2017 colocó a la representación corporativa bajo disputa. A nivel teórico, el análisis cuestiona los enfoques liberales que otorgan una igualdad formal a los intereses y actores que participan al interior de las instituciones corporativas (Lanzaro, 1998). Cualquier dinámica institucional de negociación que involucre distintos actores no puede ser justa e igualitaria cuando los intereses que allí participan no tienen el mismo peso ni las mismas condiciones para enfrentarse. La igualdad formal, así, se desvanece al momento de iniciar el juego de la negociación política. Ésta pone de manifiesto las desigualdades de aquellos en términos de su origen, fuerza y permeabilidad ante la injerencia de otros actores o estructuras, como el Estado. Asimismo, los enfoques marxistas también adolecen de ciertas limitaciones para comprender la representación de tipo corporativa. El análisis mostró cómo los intereses de los distintos sectores representados (trabajadores y empresarios) no pueden deducirse a priori de las condiciones económicas generales ni de sus posiciones en las estructuras económico-sociales, como tampoco puede definirse de forma determinante un "interés estatal" (pro-capital). Tampoco puede estipularse que la lucha fundamental se da entre estos dos tipos de intereses. Al interior del campo de poder laboral, también son las distintas categorías de trabajadores los que antagonizan entre sí.

A nivel empírico, se puede identificar cuatro grandes conclusiones. Primero, que el proceso de construcción de representación socio-política al interior del CONADES/CNTS por parte del sector empresarial es más fluido, lineal y carente de conflictos en relación al generado por el sector de los trabajadores, el cual incurre en constantes enfrentamientos por ocupar posiciones dentro del Consejo y arrogarse la representación de los trabajadores. Esto les permite a los empresarios ejercer un mayor poder en relación a los trabajadores. El capital económico y simbólico con que cuentan, la cohesión interna que mantiene el sector y por el contrario, la fragmentación del campo sindical que representa a los trabajadores del Ecuador, contribuyen a su fortalecimiento.

En segundo lugar, la fragmentación sindical no sólo fortalece la posición de los empresarios al interior del Consejo, sino que dificulta el proceso de representación de los trabajadores y al mismo tiempo contribuye a que el Estado tenga mayor control de la negociación corporativa. Tercero, el Gobierno ha ejercido influencia en la definición de la representación tanto de los trabajadores como empleadores a través de cambios en la normativa que regula al CONADES y el impulso a la creación de nuevas organizaciones sindicales como la CUT. 
Por último, los cambios en la representación del sector de los trabajadores (el desplazamiento del FUT en favor de la CUT) mostró que los intereses de los trabajadores y de la dirigencia sindical se fueron configurando de acuerdo a la correlación de fuerzas, las situaciones económicas del país y las negociaciones políticas con el gobierno de turno. En 2016, por ejemplo, se dio la situación inédita en el período bajo estudio de que los dirigentes de los trabajadores acordaron con los empresarios el salario básico unificado, aún a sabiendas de que los perjudicaría. Este cambio en la representación de los trabajadores, más allá de significar un empoderamiento empresarial porque fragmenta al campo sindical, también puede considerarse una ampliación democrática de la participación, en la medida que el Estado habilita la intervención de centrales y confederaciones sindicales que ya no se cobijan bajo la estructura del FUT por "haber perdido representatividad" e incluye a trabajadores históricamente no reconocidos como tales. Esto puede entonces interpretarse como una reparación histórica de sectores largamente perjudicados por las estructuras clasistas y Estados poco preocupados por la incorporación de las mayorías.

\section{Apoyos y soporte financiero de la investigación}

La investigación cuyos resultados se presentan en este artículo fue financiada por Grupo FARO, (Ecuador). Agradezco a Rodrigo Adriel Iturriza por su invaluable apoyo en la investigación, a quien no responsabilizo por las ideas vertidas en este texto.

\section{Bibliografía}

Achig, L., \& Neira, T. (1989). Movimiento obrero ecuatoriano y proceso sindical (los orígenes 1880-1938). Revista IDIS, 21, 69-166.

Aguiar, V. (2007). El Mercado Laboral Ecuatoriano: Propuesta de una reforma. Edición electrónica. Recuperado de: https://bit.ly/2P78GVz

Burbano de Lara, F. (2006). Estrategias para sobrevivir a la crisis del Estado. Empresarios, política y partidos en Ecuador. En Eduardo Basualdo y Enrique Arceo, Neoliberalismo y sectores dominantes. Tendencias globales y experiencias nacionales. Buenos Aires: CLACSO, Consejo Latinoamericano de Ciencias Sociales. 
Coronel, V. (2013) Justicia laboral y formación del Estado como contraparte ante el capital transnacional en Ecuador (1927-1938). Illes i imperis, 15, 171-193.

Herrera, G. (2015). Situación, estrategia y contexto de los sindicatos en el Ecuador. Documentos de Trabajo CLACSO-UMET "Nuevos modelos sindicales en América Latina y el Caribe”. Buenos Aires: CLACSO. Recuperado de: https://bit.ly/38F5J6E

Lanzaro, J. (Comp.). El fin del siglo del corporativismo. Venezuela: Nueva Sociedad. Marega, M. (2015). Trabajadores, sindicatos y Estado en Ecuador. Reconfiguraciones de la relación Estado-sindicalismo petrolero público. Tesis de Maestría. Quito: FLACSO.

Oleas, J. (2013). Ecuador 1972-1999. Del desarrollismo petrolero al ajuste neoliberal. Tesis de Doctorado en Historia. Quito: Universidad Andina Simón Bolívar.

Ospina Peralta, P. (2009). Corporativismo, estado y revolución ciudadana. El Ecuador de Rafael Correa. En Estado, movimientos sociales y gobiernos progresistas. Quito: Instituto de Estudios Ecuatorianos.

Posso, C. (2013). El retorno de Ulises. Estado y participación política. Conflicto UNE-Gobierno. Tesis de Maestría en Ciencias Políticas. Quito: FLACSO.

Ramírez Gallegos, F. (2012) Despliegues de la autonomía estatal en el Ecuador de la Revolución Ciudadana. Debates y combates, 4, 115-150.

Schmitter, P. (1998). ¿Continúa el siglo del corporativismo? En J. Lanzaro (Comp.), El fin del siglo del corporativismo. Venezuela: Nueva Sociedad.

Senplades (2014). Construcción de un Estado democrático para el Buen Vivir. Quito: SENPLADES. Recuperado de: https://bit.ly/2HC0t7J

Stoessel, S. (2017). État et représentation politique dans l'Équateur contemporain: le cas des transporteurs syndiqués. Cahiers D’Amérique Latine, 83, 3352. https://doi.org/10.4000/cal.4450

Velasco, M (1987). El movimiento obrero en Ecuador: propuestas para el análisis de sus dimensiones objetivas y sus determinaciones. Ecuador Debate, $13,25-45$.

Ycaza, P. (1991) Historia del movimiento obrero ecuatoriano. Quito: CEDIME, CIUDAD. 